\title{
SISTEMAS AGROFLORESTAIS: LIMITES E POTENCIALIDADES NO CONTEXTO SÓCIO-POLÍTICO AMBIENTAL DO SUDESTE PARAENSE
}

\author{
Alice Cardoso da Silva ${ }^{1}$; William Santos de Assis ${ }^{2}$ \\ ${ }^{1}$ Discente do curso de Agronomia, Faculdade de Ciências Agrárias de Marabá (FCAM), Universidade Federal do Pará \\ (UFPA), Marabá, Pará. E-mail: alice-car@ hotmail.com. \\ ${ }^{2}$ Prof. Dr. Coordenador do Laboratório Sócioagronomico (Lasat) do Núcleo de Ciências Agrárias e Desenvolvimento \\ Rural (NCARD) e Vice-Diretor da FCAM, UFPA. E-mail: williamassis@ufpa.br
}

RESUMO: Na Amazônia encontra-se a maior diversidade biológica do planeta. Acredita-se que em apenas $5 \%$ da superfície terrestre esteja mais de $1 / 4$ de todas as espécies vivas. Em equilíbrio dinâmico há uma estimativa que o planeta perca uma espécie vegetal a cada mil anos, no entanto cientistas afirmam que a crescente intervenção humana nas florestas tropicais poderá causar a perda de uma espécie por dia acelerando o processo de degradação dos ecossistemas. A atividade antrópica tem causado degradação dos ecossistemas comprometendo a sustentabilidade de sistemas produtivos em diferentes escalas. A necessidade de regeneração de ecossistemas ganha importância diante da drástica situação ambiental que compromete o bem estar da vida no planeta. Assim surge o desafio de regenerar de forma planejada aquilo que fora degradado sem planejamento. Para que essa restauração venha se desenvolver efetivamente é importante o desenvolvimento de alternativas que viabilizem economicamente o desempenho da mesma por produtores rurais, empresas e órgãos governamentais. Nesse contexto os sistemas agroflorestais (SAFs) podem desenvolver papéis fundamentais de regeneração, conservação e produção sustentável. Os sistemas agroflorestais são usos e manejos da terra, onde lenhosas e arbóreas são associadas a cultivos agrícolas ou com criações animais simultaneamente em um mesmo espaço ou em sequiência temporal contribuindo com a regeneração e a conservação das características iniciais da vegetação e dos solos, além de fornecer recursos financeiros e sustentabilidade para o estabelecimento agrícola. Os SAFs desempenham um papel inovador que concilia restauração, conservação e produção, no entanto, existem limitações políticas, culturais e econômicas que favorecem ou não a frequiência dessa atividade. O presente trabalho, realizado com o apoio da Universidade Federal do Pará - UFPA, tem como objetivo realizar um estudo socioeconômico das inovações agroflorestais e seu ambiente institucional na região sudeste do Pará; verificar a importância e limitações da implantação dos Sistemas Agroflorestais na região bem como avaliar as condições necessárias e mecanismos para a implantação dessa atividade. $\mathrm{O}$ trabalho é parte do projeto de Introdução de pesquisa e extensão agroflorestal no curso de agronomia de Marabá que objetiva fortalecer a experimentação agroflorestal para superar um desequilíbrio no Projeto Político-Pedagógico (PCC) do curso, entre a capacidade de diagnosticar a realidade e a capacidade de intervenção nessa realidade. As principais ferramentas metodológicas utilizadas nessa pesquisa serão: i) Revisão bibliográfica sobre Sistemas Agroflorestais na Amazônia; ii) levantamento de informação sobre políticas públicas de incentivo a implantação de Sistemas Agroflorestais; iii) entrevista com pessoas-chave e; iv) sistematização de experiências implantadas por agricultores e/ou instituições da região sudeste do Pará. Será dada especial atenção as iniciativas e programas que tenham como lócus de ação a região sudeste do Pará e em especial o município de Marabá. Espera-se ao final do percurso desse estudo: obter uma descrição geral do ambiente institucional referentes aos Sistemas Agroflorestais como políticas, programas existentes e instituições envolvidas; montar um quadro geral sobre as iniciativas de SAFs no âmbito local; fazer uma leitura crítica sobre potencialidades e limitações para implantação de SAFs na região; descrição sucinta de uma experiência de SAFs na região; e produção de um artigo.

PALAVRAS-CHAVE: Amazônia, agroecossistemas, manejo ecológico. 